\title{
Imidocarb dipropionate lacks efficacy against Theileria haneyi and fails to consistently clear Theileria equi in horses co-infected with $\mathrm{T}$. haneyi
}

Kelly Sears ${ }^{1}$, Donald Knowles ${ }^{1}$, Kelcey Dinkel ${ }^{1}$, Philip Mshelia ${ }^{1,3}$, Cynthia Onzere ${ }^{1}$, Marta Silva ${ }^{1,4}$, Lindsay Fry ${ }^{1,2^{\star}}$

${ }^{1}$ Program in Vector-borne Diseases, Department of Veterinary Microbiology and Pathology, Washington State University, College of Veterinary Medicine, Pullman, WA, USA; ${ }^{2}$ USDA - ARS, Animal Disease Research Unit, Pullman, WA, USA; ${ }^{3}$ Department of Veterinary Medicine, Ahmadu Bello University, Zaria, Kaduna, Nigeria. ${ }^{4} \mathrm{CureVac}$ AG, Tubingen, Germany.

${ }^{*}$ Corresponding author: Lindsay.Fry@usda.gov

Abstract: Control of Theileria equi, the primary cause of equine theileriosis, is largely reliant on acaracide use and chemosterilization with imidocarb dipropionate (ID). However, it is currently unknown if ID is effective against Theileria haneyi, the recently identified second causative agent of equine theileriosis, or if the drug maintains effectiveness against $T$. equi in the presence of $T$. haneyi co-infection. The purpose of this study was address these questions using ID treatment of the following three groups of horses: 1. Five $T$. haneyi infected horses; 2 . Three $T$. haneyi-T. equi infected horses; and 3. Three T. equi-T. haneyi infected horses. Clearance was first evaluated using nPCR for each Theileria sp. on peripheral blood samples. ID failed to clear $T$. haneyi in all three groups of horses, and failed to clear $T$. equi in $2 / 3$ horses in group two. For definitive confirmation of infection status, horses in groups two and three underwent splenectomy post-treatment. The $T$. equi-nPCR-positive horses in group two developed severe clinical signs and were euthanized. Remaining horses exhibited moderate signs consistent with $T$. haneyi. Our results demonstrate that ID therapy lacks efficacy against $T$. haneyi, and $T$. haneyi-T. equi co-infection may interfere with ID clearance of T. equi.

Keywords: Equine theileriosis, Theileria haneyi, treatment, imidocarb diproprionate 


\section{Introduction}

The apicomplexan hemoparasite Theileria equi is the primary causative agent of equine theileriosis and is endemic in both tropical and subtropical regions of the world. Distribution of infection is dependent on the presence of competent ticks and/or practices leading to iatrogenic transmission. The few remaining, non-endemic countries employ stringent importation testing and prohibit entry of positive equids, resulting in "ongoing economic and regulatory challenges regarding international horse transport."[1] This testing barrier imposes a significant economic impact on the equine industry of endemic countries that are subsequently unable to export to non-endemic countries [2].

Regardless of location during natural infection of naïve equids, $T$. equi induces clinical signs ranging from acute, severe hemolytic anemia and resultant weakness, hemoglobinuria, and death, to inapparent infection, with the natural determinants of disease severity largely unknown[3]. In an experimental setting, however, T. equi is invariably fatal in splenectomized equids with splenectomized equids developing acute, severe disease with rapidly escalating parasitemia and subsequent anemia as indicated by decline in packed cell volume (PCV)/hematocrit (HCT). These equids eventually succumb to disease due to massive hemolytic crisis due to unchecked parasite replication and subsequent erythrolysis[4-6]. Fortunately, horses are rarely splenectomized outside of the research setting, where splenectomy is employed as a means to verify chemotherapeutic parasite clearance or for development of parasite stabilates for future inoculations $[4,5,7,8]$. While $T$. equi infection of splenectomized horses is fatal, spleen-intact horses that survive acute infection transition to a persistent, asymptomatic infection state and remain silent reservoirs for transmission [3].

Immune responses that give rise to the transition from acute, severe disease to inapparent infection are only partially defined for $T$. equi. The development of specific immunoglobulin isotypes ( $\lg G 1,4,7)$ correlates with control of parasitemia during the acute phase of infection, and additional isotypes, $\lg G 3$ and $\lg G 5(\lg G(T))$, appear after the resolution of parasitemia $[9,10]$. Since robust antibody responses play a role in parasite control, the primary diagnostic assay used for both importation testing and identification of carrier equids is a competitive ELISA, which measures $T$. equi-specific antibodies to EMA-1 in horse serum [7,11].

Despite the apparent role of adaptive immunity in parasite control, a successful vaccine has yet to be developed, due in large part to the relative paucity of data on the equine immune response. The significant genetic diversity within $T$. equi clades further complicates vaccine development efforts. Five distinct $T$. equi clades are currently recognized [12], and recent work has provided sufficient evidence to define a second species of equine-infective Theileria, known as Theileria haneyi [13]. In contrast to $T$. equi, T. haneyi (Eagle Pass strain) induces minimal clinical disease in spleen-intact horses [13,14], characterized by mild changes in PCV and occasional development of fever during the acute phase $[13,14]$.

Epidemiological data documenting the prevalence of this new species is limited; however, it has been identified in South Africa, Nigeria, The Gambia, and in horses along the US-Mexico border [13,15-17]. Prevalence surveys in The Gambia, Nigeria, 
and South Africa have also reported co-infection of horses with T. equi and T. haneyi or triple infection with T. equi, T.haneyi, and B. caballi [15-17]. Both organisms cause persistent, asymptomatic infection, and both are capable of superinfection in the presence of humoral immunity to the other [14]. Long-term studies suggest that the majority of co-infected horses are unable to spontaneously clear either species, and, as there is not yet a vaccine, control strategies are centered on acaricide use, rigorous surveillance testing, and the use of chemotherapeutic drugs to clear infection.[3,14]

Currently, the only medication known to be effective in achieving $T$. equi chemosterilization in vivo is imidocarb dipropionate (ID), an aromatic diamidine and carbanilide derivative $[7,18,19]$. Frerichs et al initially validated the current ID treatment regimen of $4 \mathrm{mg} / \mathrm{kg}$, administered every 72 hours for 4 doses [18]. However, clearance was not achieved in all horses even after two courses of ID [18]. ID is also hepato- and nephrotoxic at high doses, and has significant side effects at therapeutic doses attributed to its anticholinesterase effects, including colic, diarrhea, and salivation $[18,20,21]$. These side effects are often ameliorated using co-administration of anticholinergic and anti-spasmodic medications $[18,21,22]$. In equine piroplasmosis, chemosterilization, or clearance, is defined by inability to detect organisms using nested PCR (nPCR) assays and/or failure to transmit the organism to a naïve, splenectomized horse via whole blood transfer [7,23]. However, neither of the aforementioned criteria are utilized by the United States or by the OIE as definitive tests for importation $[3,23]$.

Although ID is quite effective, rare horses remain $T$. equi-positive despite two rounds of treatment, with only $1 / 14$ horses with a Florida, USA isolate of $T$. equi failing to clear and $1 / 6$ remaining infected with a Peruvian strain $[18,19]$. In a recent study of horses infected with a $T$. equi strain from Texas, USA, 24/25 horses were successfully cured after a single course of treatment, and one horse was not cleared after two rounds of ID treatment [7]. Furthermore, in vitro studies suggest the development of IDresistance by some $T$. equi strains following ID exposure [24]. Given the recent recognition of $T$. haneyi in the U.S., the lack of information regarding its susceptibility to ID, and the presence of horses super-infected with T. equi and T. haneyi at the U.S.Mexico border, the goals of this study were: 1 . To assess whether ID treatment is an effective chemosterilization agent for $T$. haneyi infected horses; and 2 . To determine if $T$. haneyi co-infection interferes with ID clearance of $T$. equi infection in horses.

\section{Results}

\subsection{T. haneyi experimental infection}

For horses in group 1, T. haneyi infection resulted in mild to inapparent disease. Three of five horses developed fevers for 1-5 days post-inoculation, and a single horse developed mild changes in HCT. Clinical and erythrocyte parameters were within normal limits in all group 1 horses by day 60 post-inoculation. Horses in groups 2 and 3 exhibited similar clinical signs following stabilate inoculation of naïve horses for group 2 and $T$. equi infected horses for group 3 as previously described [14]. 


\subsection{Imidocarb diproprionate treatment}

During both courses of ID treatment, horses overall exhibited minimal negative side effects immediately following ID administration. Two group 1 horses did develop signs of colic necessitating administration of flunixin meglumine during their first round of ID treatment. Colic signs resolved with medication administration. All horses developed changes in muscle and/or liver enzymes (creatine kinase (CK), aspartate aminotransferase (AST), and gamma-glutamyl transferase (GGT)) and/or developed injection site swelling within 3-6 days of treatment (Table 1). Muscle and liver enzyme levels declined to normal prior to administration of the second course of treatment for all 3 groups, and again prior to splenectomy for groups 2 and 3 . All 3 groups of horses following the second course of ID administration were asymptomatic for equine piroplasmosis and negative by blood smear cytology regardless of persistent low-level infections detected via nPCR. Groups 2 and 3 also remained asymptomatically infected at the time of splenectomy (Table 2).

Table 1. Summary of incidence of elevation in serum enzymes and injection site reactions following each 4-dose series of ID treatment

\begin{tabular}{|c|c|c|c|c|c|c|c|c|c|}
\hline & & \multicolumn{4}{|c|}{$1^{\text {ST }}$ Course of Treatment } & \multicolumn{4}{|c|}{$2^{\text {nd }}$ Course of Treatment } \\
\hline $\begin{array}{c}\text { Horse } \\
\text { number }\end{array}$ & Group & CK & AST & GGT & $\begin{array}{l}\text { Injection } \\
\text { site } \\
\text { swelling }\end{array}$ & CK & AST & GGT & $\begin{array}{l}\text { Injection } \\
\text { site } \\
\text { swelling }\end{array}$ \\
\hline 270 & 1 & $\uparrow$ & $\uparrow$ & & $N$ & $\uparrow$ & $\uparrow$ & & $N$ \\
\hline 364 & 1 & $\uparrow$ & $\uparrow$ & & $\mathrm{N}$ & $\uparrow$ & $\uparrow$ & $\uparrow$ & $\mathrm{N}$ \\
\hline 776 & 1 & $\uparrow$ & $\uparrow$ & $\uparrow$ & $Y$ & & & & $\mathrm{~N}$ \\
\hline 777 & 1 & $\uparrow$ & $\uparrow$ & & $\mathrm{Y}$ & & & & $\mathrm{N}$ \\
\hline 784 & 1 & $\uparrow$ & $\uparrow$ & & $Y$ & & & & $\mathrm{~N}$ \\
\hline 273 & 2 & $\uparrow$ & & & $\mathrm{Y}$ & & $\uparrow$ & & $\mathrm{Y}$ \\
\hline 280 & 2 & $\uparrow$ & & & $\mathrm{N}$ & $\uparrow$ & & & $\mathrm{N}$ \\
\hline 283 & 2 & $\uparrow$ & $\uparrow$ & & $\mathrm{N}$ & $\uparrow$ & & & $\mathrm{N}$ \\
\hline 275 & 3 & $\uparrow$ & $\uparrow$ & $\uparrow$ & $\mathrm{Y}$ & $\uparrow$ & $\uparrow$ & & $\mathrm{Y}$ \\
\hline 277 & 3 & $\uparrow$ & $\uparrow$ & $\uparrow$ & $\mathrm{Y}$ & $\uparrow$ & $\uparrow$ & $\uparrow$ & $\mathrm{Y}$ \\
\hline 278 & 3 & $\uparrow$ & $\uparrow$ & $\uparrow$ & $\mathrm{N}$ & $\uparrow$ & $\uparrow$ & $\uparrow$ & $\mathrm{Y}$ \\
\hline
\end{tabular}


Table 2. T. haneyi and T. equi $\mathrm{nPCR}$ results at serial time points following each course of ID treatment.

\section{T. haneyi $\mathrm{nPCR}$}

\begin{tabular}{cccccccc}
\hline $\begin{array}{c}\text { Horse } \\
\text { number }\end{array}$ & Group & $\begin{array}{c}\text { Pre- } \\
\text { Treatment } \\
\# 1\end{array}$ & $\begin{array}{c}\text { Post- } \\
\text { Treatment } \\
\# 1^{\mathrm{a}}\end{array}$ & $\begin{array}{c}\text { Pre- } \\
\text { Treatment } \\
\# 2\end{array}$ & $\begin{array}{c}\text { Post- } \\
\text { Treatment } \\
\# 2^{\mathrm{a}}\end{array}$ & $\begin{array}{c}\text { Pre- } \\
\text { Surgery }\end{array}$ & $\begin{array}{c}\text { Post- } \\
\text { Surgery }\end{array}$ \\
\hline 270 & 1 & + & + & + & + & $\mathrm{N} / \mathrm{A}$ & $\mathrm{N} / \mathrm{A}$ \\
\hline 364 & 1 & + & + & + & + & $\mathrm{N} / \mathrm{A}$ & $\mathrm{N} / \mathrm{A}$ \\
\hline 776 & 1 & + & - & + & + & $\mathrm{N} / \mathrm{A}$ & $\mathrm{N} / \mathrm{A}$ \\
\hline 777 & 1 & + & + & + & + & $\mathrm{N} / \mathrm{A}$ & $\mathrm{N} / \mathrm{A}$ \\
\hline 784 & 1 & + & + & + & + & $\mathrm{N} / \mathrm{A}$ & $\mathrm{N} / \mathrm{A}$ \\
\hline 273 & 2 & + & + & + & + & + & + \\
\hline 280 & 2 & + & - & + & + & + & + \\
\hline 283 & 2 & + & + & + & + & + & + \\
\hline 275 & 3 & + & - & - & + & + & + \\
\hline 277 & 3 & + & + & + & + & + & + \\
\hline 278 & 3 & + & + & + & + & + & + \\
\hline
\end{tabular}

T. equi nested PCR

\begin{tabular}{cccccccc}
\hline $\begin{array}{c}\text { Horse } \\
\text { number }\end{array}$ & Group & $\begin{array}{c}\text { Pre- } \\
\text { Treatment } \\
\# 1\end{array}$ & $\begin{array}{c}\text { Post- } \\
\text { Treatment } \\
\# 1^{\mathrm{a}}\end{array}$ & $\begin{array}{c}\text { Pre- } \\
\text { Treatment } \\
\# 2\end{array}$ & $\begin{array}{c}\text { Post- } \\
\text { Treatment } \\
\# 2^{\mathrm{a}}\end{array}$ & $\begin{array}{c}\text { Pre- } \\
\text { Surgery }\end{array}$ & $\begin{array}{c}\text { Post- } \\
\text { Surgery }\end{array}$ \\
\hline 273 & 2 & + & + & - & - & +- & + \\
\hline 280 & 2 & + & - & - & - & - & - \\
\hline 283 & 2 & + & + & + & + & $+/-$ & + \\
\hline 275 & 3 & + & - & - & - & - & - \\
\hline 277 & 3 & + & - & - & - & - & - \\
\hline 278 & 3 & + & - & - & - & - & -
\end{tabular}

aPost-treatment time points were 40-60 days following the last dose of ID for the associated course of treatment. "+" = Positive, "-" = Negative, N/A = Not Applicable

\subsection{Imidocarb dipropionate fails to clear T. haneyi infection}

Following two courses of ID treatment, all horses in all three groups remained positive for $T$. haneyi by nPCR (Table 2). In a single horse from each group (3 of 11 total horses), parasitemia transiently dropped below detectable levels at 1-2 time points after the first course of treatment. However, parasitemia likely subsequently increased 
to sufficiently allow detection by nPCR at all successive time points following the second course of treatment and prior to splenectomy for groups 2 and 3 (Table 2).

2.4. Imidocarb dipropionate fails to clear T. equi in a subset of horses co-infected with $T$. equi and T. haneyi.

Following two ID treatment courses, co-infected horses in groups 2 and 3 were regularly evaluated using $T$. equi $\mathrm{nPCR}$ and cELISA for evidence of parasite clearance. After the first round of ID therapy, 4/6 horses in these two groups were negative for $T$. equi by $\mathrm{nPCR}$, and $5 / 6$ horses were negative for $T$. equi by $\mathrm{nPCR}$ prior to and after the second course of therapy. The T. equi nPCR was performed on DNA from blood collected at multiple, post-ID treatment/pre-splenectomy time points. At these time points, two horses from group 2 had variable $T$. equi nPCR results, and all three horses in group 2 maintained T. equi cELISA values greater than $80 \%$ (Table 2)(Figure 1). In contrast, all horses in group 3 exhibited declining values on the $T$. equi cELISA test over time prior to splenectomy (Figure 1).

To definitively determine whether ID had successfully cleared the T. equi-T. haneyi co-infected horses of $T$. equi, all six horses in groups 2 and 3 were splenectomized approximately 657-743 days after completion of the second ID treatment regimen. Intraerythrocytic Theileria sp. parasites were detected in all horses within seven days following splenectomy by blood smear. Horses 273 and 283 developed severe, acute disease characterized by fever, hemoglobinuria, icterus, leukocytosis (neutrophilia), thrombocytopenia, and a progressive, rapid decline in hematocrit (19-29\%) that corresponded with rapidly rising parasitemia of $25-41 \%$. Both horses were found to be positive for $T$. equi by $\mathrm{nPCR}$, and were humanely euthanized.

The surviving four horses were confirmed via nPCR to be infected with $T$. haneyi alone. Each of these animals developed moderate clinical signs consistent with equine theileriosis, including fever, icterus, variable leukocytosis (neutrophilia and monocytosis), thrombocytopenia, and anemia. Peak parasitemia was observed between days 14-19 and ranged from 7.5-14.4\%. In these horses, the hematocrit declined to a nadir of $10-23.6 \%$ from days 22 to 31 post-splenectomy (Table 3 ). Following splenectomy, two of the four surviving horses (277 \& 278) showed a marked increase in their T. equi cELISA values, and all surviving horses continued to have values above the positive cutoff of $40 \%$ inhibition (Figure 2). All clinical abnormalities resolved following the initial recrudescence phase post-splenectomy, and horses remained persistently, asymptomatically infected with $T$. haneyi, but not $T$. equi, 3-6 months later. 


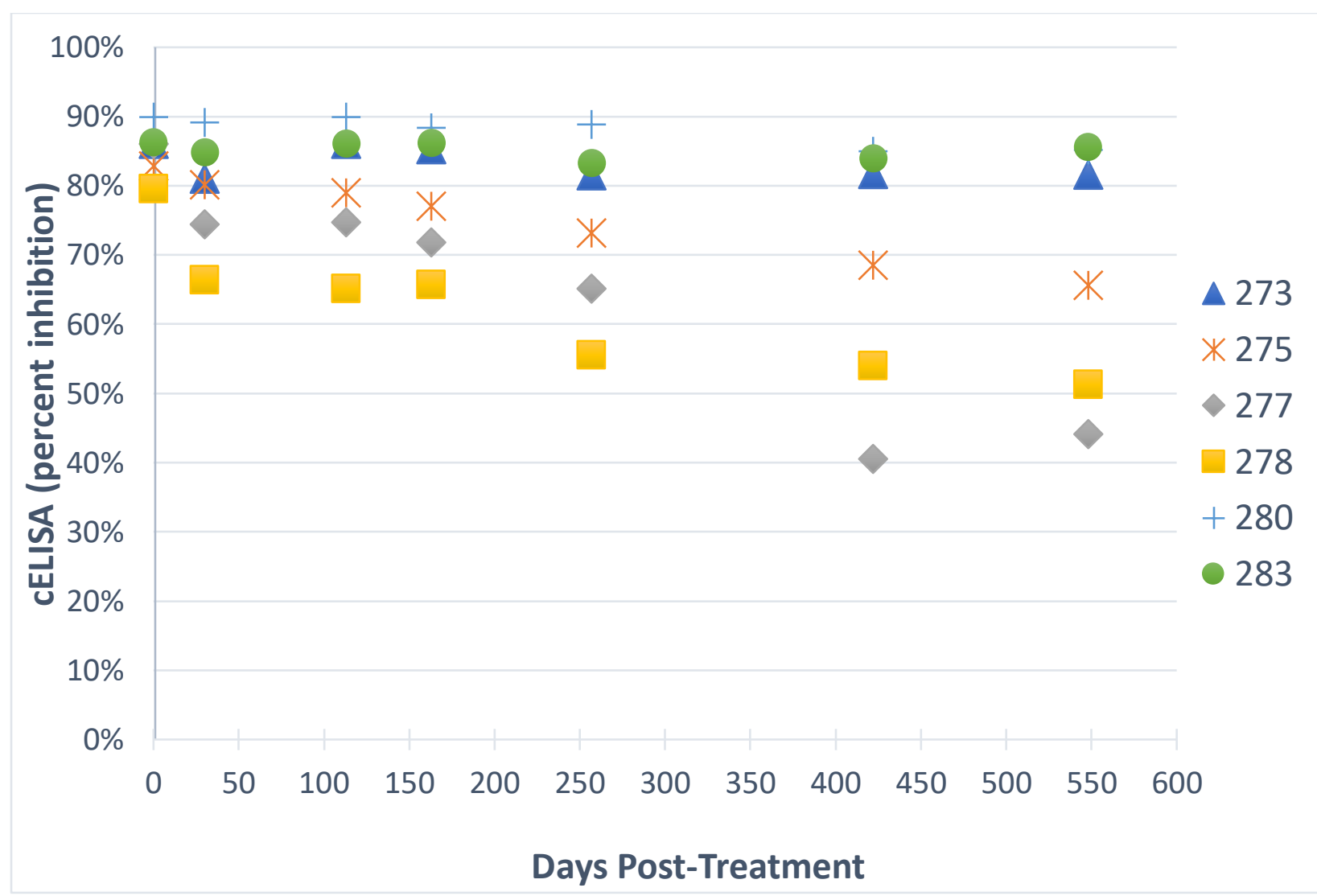

Figure 1. Change in T. equi cELISA values following two courses of imidocarb dipropionate treatment. Day zero is the day of the last dose of the second round of treatment. A horse is considered to be positive by cELISA when the percent inhibition is greater than $40 \%$. 


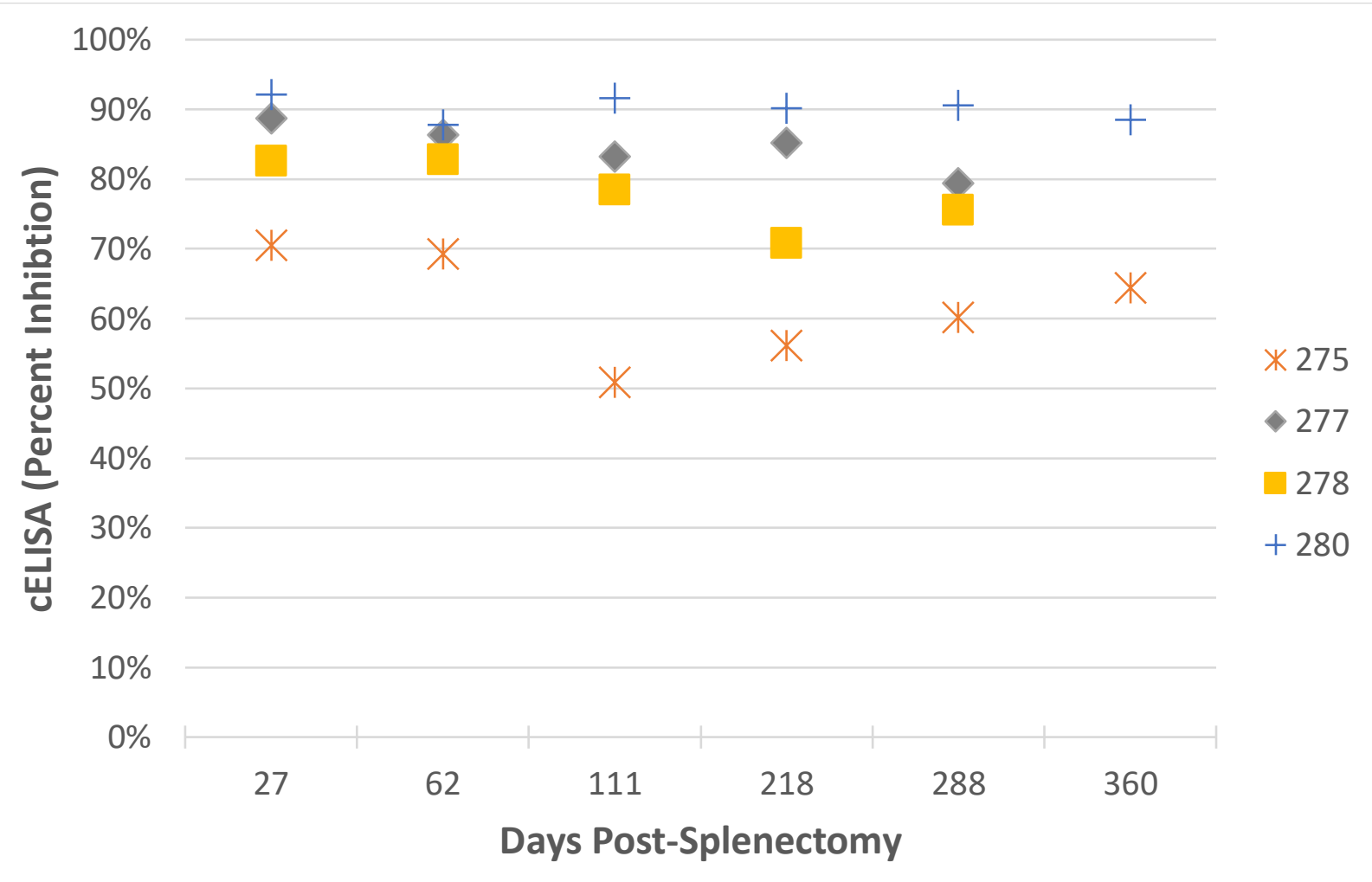

Figure 2. Changes in T. equi cELISA post-splenectomy in surviving horses. Day zero is the day of splenectomy for each horse. Splenectomies were performed asynchronously.

Table 3. Summary of hematocrit and parasitemia post-splenectomy.

\begin{tabular}{cccccll}
\hline $\begin{array}{c}\text { Horse } \\
\text { number }\end{array}$ & Group & $\begin{array}{c}\text { Time to } \\
\text { Peak } \\
\text { PPE } \\
\text { (days) }\end{array}$ & $\begin{array}{c}\text { Peak } \\
\text { PPE } \\
(\%)\end{array}$ & $\begin{array}{c}\text { HCT } \\
\text { nadir } \\
\text { (\%) }\end{array}$ & Outcome & $\begin{array}{c}\text { T. equi } \\
\text { nPCR }\end{array}$ \\
\hline 280 & 2 & 17 & 7.69 & 17.8 & Survived & Negative \\
\hline 273 & 2 & 9 & 25.1 & 19.5 & Euthanized & Positive \\
\hline 283 & 2 & 10 & 40.46 & 28.9 & Euthanized & Positive \\
\hline 275 & 3 & 14 & 7.5 & 23.4 & Survived & Negative \\
\hline 277 & 3 & 17 & 10.58 & 12.6 & Survived & Negative \\
\hline 278 & 3 & 19 & 14.4 & 10 & Survived & Negative \\
\hline
\end{tabular}

\section{Discussion}

The data presented demonstrate that imidocarb dipropionate is not effective for chemosterilization of horses infected with $T$. haneyi. More importantly, our data demonstrate that ID fails to clear $T$. equi in a subset of horses infected with both $T$. equi 
and $T$. haneyi. This is troubling due to the fact that both $T$. haneyi and $T$. equi are endemic in countries across the world, and several naturally co-infected horses have already been identified (unpublished data). Inter-country movement of $T$. equi-infected horses is tightly constrained, and ID therapy is a cornerstone of $T$. equi clearance for transport and trade. If ID fails to clear $T$. equi in co-infected animals, the global equine industry could face tremendous economic losses. Furthermore, persistent piroplasmosis can lead to reduced performance in horses used for athletic events or farming/traction purposes, even in the absence of other appreciable clinical signs [3,25]. The absence of any effective treatment for $T$. haneyi, and the lack of a consistently effective treatment for $T$. equi in co-infected horses, will significantly impact producers, farmers, and the international movement of equine athletes.

In our study, administration of imidocarb dipropionate resulted in local (injection site swelling) and systemic changes (muscle and liver enzyme elevations) consistent with previous studies [20,21]. These changes are associated with the hepatoxic and nephrotoxic effects of ID. Fortunately, elevation of biochemical parameters resolved without intervention, suggesting irreversible damage was not sustained. The anticholinesterase effects (salivation, diarrhea, colic) were mitigated with Buscopan administration in our cohort, and mild colic was observed in only two horses following administration of ID [20].

The T. equi cELISA, and nPCR for $T$. equi and $T$. haneyi were utilized prior to splenectomy to assess infection status since horses in all experimental groups remained largely asymptomatic. In general, horses that have been successfully treated for Texas-isolates of $T$. equi exhibit a decline in cELISA values over time [19,23]. However, even when infection is eliminated, it can take years for the cELISA values to fall below the $40 \%$ positive cut-off [23]. Furthermore, horses may become transiently negative by $\mathrm{nPCR}$ post-treatment, but subsequently test positive again after several months [26]. Thus, to confirm whether parasite clearance had occurred, we splenectomized all horses in our $T$. equi/ $T$. haneyi co-infection groups several months after their second ID treatment course. Removal of splenic control allows rapid amplification of $T$. equi parasitemia, resulting in patent clinical disease in persistently infected, previously asymptomatic, horses [4,5,8,27].

ID appears to be inconsistently effective in clearing $T$. equi in the presence of $T$. haneyi co-infection. The mechanism responsible for therapeutic failure in a subset of horses is not yet known; however, authors have suggested within-host competition between resistant and non-resistant strains can play a role in the evolution of resistance [28]. Furthermore, Hansen and colleagues demonstrated that "drug sensitive strains can competitively exclude drug-resistant strains in untreated hosts" [29], and chemotherapeutic treatment can result in competitive facilitation or release of drug resistant organisms [29]. The same $T$. equi stabilate was utilized to infect all six of the superinfected horses in this study. The stabilate was developed from a splenectomized horse that had had received a blood transfusion from a persistently infected horse. The ID-susceptibility of the parasites within the splenectomized horse, and the blood that infected that horse, is unknown; however, the source animal was from the group of 25 naturally infected horses in TX, of which, 24 were successfully treated with ID. Interestingly, three of four surviving horses were first infected with $T$. equi and then superinfected with $T$. haneyi, while both horses that remained dually infected were first 
infected with $T$. haneyi and then superinfected with $T$. equi, suggesting that order of infection could play a role in the capacity of ID to clear $T$. equi. Other research scientists have speculated on the role infection sequence may play in disease dynamics and severity [30]. However, further studies, utilizing a greater number of animals, are required to substantiate or refute this observation.

Overall, identification of effective control strategies capable of successfully eliminating vector-borne equine pathogens are growing in demand as vector species once constrained to certain regions of the world expand into previously uninhabitable territories due to climate change and environmental alteration by human and animal movement. As the development of an equine piroplasmosis vaccine remains elusive for the near future, and imidocarb diproprionate appears to be ineffective against $T$. haneyi and variably effective against $T$. equi in the presence of $T$. haneyi co-infection, additional studies are warranted to find more effective chemotherapeutic drugs capable of clearing all causative agents of equine theileriosis. Numerous compounds have been screened for in vitro efficacy against $T$. equi, but none have yet been assessed in clinical trials [31-33]. In addition, numerous new compounds have shown in vitro efficacy against related protozoa, including Cryptosporidia sp., Toxoplasmosis sp, and Babesia sp. [34,35]. Thus, future work should focus on expanded in vitro screening of compound libraries, coupled with in vivo equine studies to assess clearance of $T$. equi and $T$. haneyi in the equine host.

\section{Materials and Methods}

\subsection{Horses}

Eleven adult ponies (5 geldings and 6 mares), were used in this study, and were divided into three groups. All horses were confirmed $T$. equi and $T$. haneyi-negative using nPCR on whole blood (described below) prior to the onset of the study. Group assignments by horse number are shown in Table 4 . Horses in group 1 were infected with T. haneyi only. Within this group, horse 270 was infected with T. haneyi (Eagle Pass isolate) via whole blood transfusion from a known positive horse [13], and the remaining four horses were infected with $T$. haneyi (Eagle Pass) via intravenous injection of $2-4 \mathrm{~mL}$ of stabilate derived from the blood of a known positive horse $(8.8 \%$ percent parasitized erythrocytes (PPE)[13]. Horses in groups 2 and 3 were infected via intravenous inoculation with $2 \mathrm{~mL} T$. haneyi (Eagle Pass) infected frozen erythrocyte stabilate, (12\% PPE) and $1 \mathrm{~mL}$ T. equi (Texas isolate) stabilate (38\% PPE). Group 2 was infected with $T$. haneyi first, and then superinfected with $T$. equi, and group 3 was initially infected with $T$. equi and then superinfected with $T$. haneyi [14]. For all stabilate infections, stabilates were thawed slowly at room temperature, combined with either $10 \%$ normal horse serum in phosphate buffered saline or autologous serum and then injected intravenously over 2-3 minutes. For all horses, $T$. haneyi and T. equi infection status was confirmed using nPCR at multiple time points prior to treatment. Horses were housed in pairs. All animal experiments were approved by the Washington State University and University of Idaho Institutional Animal Care and Use Committees, ASAF numbers 4973 and 6241 (WSU) and 2016-18 and 2016-28 (UI). 
Table 4. Horses utilized in the study

\begin{tabular}{|c|c|c|}
\hline Horse ID & $\begin{array}{l}\text { Group } \\
\text { number }\end{array}$ & Inoculation \\
\hline 270 & \multirow{5}{*}{ 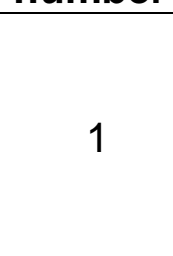 } & T. haneyi \\
\hline 364 & & T. haneyi \\
\hline 776 & & T. haneyi \\
\hline 777 & & T. haneyi \\
\hline 784 & & T. haneyi \\
\hline 273 & \multirow{3}{*}{2} & T. haneyi/T.equi \\
\hline 280 & & T. haneyi/T.equi \\
\hline 283 & & T. haneyi/T.equi \\
\hline 275 & \multirow{3}{*}{3} & T.equil T. haneyi \\
\hline 277 & & T.equil T. haneyi \\
\hline 278 & & T.equi/ T. haneyi \\
\hline
\end{tabular}

\subsection{Blood Collection}

Blood was collected via jugular venipuncture immediately prior to inoculation and serially following inoculation. Blood was also collected immediately prior to each imidocarb dipropionate treatment and at monthly intervals thereafter. Blood was collected into both ethylenediaminetetraacetic acid (EDTA) and serum separator tubes and processed for use in diagnostic assays within two hours of collection. Serum separator tubes were centrifuged at $1500 \times \mathrm{g}$ for 10 minutes following clot formation. Serum and whole blood samples were subsequently divided into aliquots for complete blood counts (CBC), serum chemistry panels, blood smears, serologic assays, and DNA isolation for PCR. Serum and DNA samples were stored at $-20^{\circ} \mathrm{C}$.

\subsection{Imidocarb dipropionate treatment}

Horses underwent initial ID treatment (four doses, each 72 hours apart) 6 to 56 months post-inoculation. Approximately 10-15 minutes before ID injection, horses were pre-treated with $0.3 \mathrm{mg} / \mathrm{kg} \mathrm{N}$-butylscopolammonium bromide (Buscopan®, Boehringer Ingelheim, Duluth, GA, USA) via intramuscular (IM) injection in the neck. Imidocarb dipropionate (Imizol® - Merck Animal Health (Kenilworth, NJ, USA) \& Imochem120 Interchemie (Venray, The Netherlands) [7,36] was then administered IM $(4 \mathrm{mg} / \mathrm{kg})$ on the opposite side of the neck. All horses were closely monitored for one hour after ID administration for any adverse effects (colic, diarrhea, dyspnea, ptyalism, changes in attitude), and then subsequently monitored daily for injection site reactions and every 7 14 days via serum chemistry panel for evidence of renal or hepatic toxicity until values returned to within the normal range. All horses received a second course of ID treatment (4 mg/kg IM q $72 \mathrm{hr}$ for 4 doses) 2-4 months after completion of the initial treatment course. Horses that developed colic post-ID administration were treated with flunixin meglumine $1.1 \mathrm{mg} / \mathrm{kg}$ IV (Prevail ${ }^{\mathrm{TM}}$ Bimeda-MTC Animal Health, Inc; Cambridge, ON Canada). 


\subsection{T. haneyi nested PCR (genomic DNA)}

DNA was isolated from whole blood using the DNeasy Blood and Tissue Kit (Qiagen, Inc.) per the manufacturer's instructions, and was stored at $-20^{\circ} \mathrm{C}$ until analysis by nPCR. The nPCR was designed to amplify a gene target absent from the $T$. equi genome and was performed as previously described $[13,14]$. Primers utilized for the reaction were the following: External Forward 5' CCATACAACCCACTAGAG 3', External Reverse 5' CTGTCATTTGGGTTTGATAG 3', Internal Forward 5' GACAACAGAGAGGTGATT 3', and Internal Reverse 5' CGTTGAATGTAATGGGAAC 3'. [14] Briefly, for the external reaction, $12.5 \mu \mathrm{L}$ of 2X DreamTaq PCR Master Mix (Thermo Scientific, Waltham, MA), $1 \mu \mathrm{L}(10 \mu \mathrm{M})$ Fwd external primer, $1 \mu \mathrm{L}(10 \mu \mathrm{M}) \mathrm{Rev}$ external primer, $5.5 \mu \mathrm{L}$ of nuclease-free water, and $5.0 \mu \mathrm{L}$ of DNA were combined. The external reaction was carried out under the following conditions: $95^{\circ} \mathrm{C}$ for $4 \mathrm{~min}$, then 35 cycles of $95^{\circ} \mathrm{C}$ for $20 \mathrm{sec}, 63.5^{\circ} \mathrm{C}$ for $30 \mathrm{sec}$, and $72^{\circ} \mathrm{C}$ for $20 \mathrm{sec}$, and final extension at $72^{\circ} \mathrm{C}$ for $7 \mathrm{~min}$. For the internal reaction, $12.5 \mu \mathrm{L} 2 \mathrm{X}$ DreamTaq Green PCR Master Mix (Thermo Scientific, Waltham, MA), $1 \mu \mathrm{L}(10 \mu \mathrm{M})$ Fwd internal primer, $1 \mu \mathrm{L}(10 \mu \mathrm{M}) \mathrm{Rev}$ internal primer, $9.5 \mu \mathrm{L}$ of nuclease-free water, and $1 \mu \mathrm{L}$ of external reaction product were used. The internal reaction was carried out under the following conditions: $95^{\circ} \mathrm{C}$ for $4 \mathrm{~min}$, then $35 \mathrm{cycles}$ of $95^{\circ} \mathrm{C}$ for $20 \mathrm{sec}, 58.1^{\circ} \mathrm{C}$ for $30 \mathrm{sec}$, and $72^{\circ} \mathrm{C}$ for $20 \mathrm{sec}$, and final extension at $72^{\circ} \mathrm{C}$ for $7 \mathrm{~min}$.

\subsection{T. equi nested PCR (genomic DNA)}

nPCR for $T$. equi utilized primers for the ema-1 gene, which is absent from the genome of $T$. haneyi, and was performed as previously described [13] [37]. Briefly, for the external reaction, $12.5 \mu \mathrm{L}$ of $2 X$ DreamTaq PCR Master Mix (Thermo Scientific, Waltham, MA), , $1 \mu \mathrm{L} 10 \mu \mathrm{M}$ Fwd external primer, $1 \mu \mathrm{L}$ of $10 \mu \mathrm{M}$ Rev external primer, $5.5 \mu \mathrm{L}$ of nuclease-free water, and $5 \mu \mathrm{L}$ of genomic DNA were used. The external reaction was carried out under the following conditions: $95^{\circ} \mathrm{C}$ for $5 \mathrm{~min}$, then 25 cycles of $95^{\circ} \mathrm{C}$ for 20 seconds, $60^{\circ} \mathrm{C}$ for 20 seconds, $72^{\circ} \mathrm{C}$ for 20 seconds, and final extension at $72^{\circ} \mathrm{C}$ for 10 minutes. For the internal reaction, $12.5 \mu \mathrm{L}$ of $2 \mathrm{X}$ DreamTaq Green PCR Master Mix (Thermo Scientific, Waltham, MA), $1 \mu \mathrm{L} 10 \mu \mathrm{M}$ Fwd internal primer, $1 \mu \mathrm{L}$ of $10 \mu \mathrm{M}$ Rev internal primer, $9.5 \mu \mathrm{L}$ of nuclease-free water, and $1 \mu \mathrm{L}$ of external reaction product were used. The internal reaction was carried out under the following conditions: $95^{\circ} \mathrm{C}$ for $5 \mathrm{~min}$, then 25 cycles of $95^{\circ} \mathrm{C}$ for 5 seconds, $60^{\circ} \mathrm{C}$ for 5 seconds, $72^{\circ} \mathrm{C}$ for 5 seconds, and final extension at $72^{\circ} \mathrm{C}$ for 10 minutes.

\subsection{T. equi CELISA}

The World Organization for Animal Health (OIE) and United States Department of Agriculture (USDA)-approved $T$. equi regulatory diagnostic test, a competitive, enzyme-linked, immunosorbent assay (cELISA), was performed using a commercially available kit (VMRD, Pullman, WA, USA) as directed by the manufacturer. A positive result is defined as $>40 \%$ inhibition by the manufacturer. This assay was performed at regular intervals on serum from infected horses to monitor the serologic response to $T$. equi. Specifically, on days $30,113,163,257,422$, and 548 after the second round of 
treatment. cELISA values were subsequently evaluated post-splenectomy on a time point within the following ranges due to surgeries occurring asynchronously: Days 27$33,54-62$, 111-153, 218-239, 288-309, and 360-381.

\subsection{Splenectomy of ID-treated, co-infected horses - T. equi clearance confirmation}

Following the second course of ID treatment, horses in groups two and three underwent splenectomy at the Washington State University Veterinary Teaching Hospital [38] in order to definitively determine whether ID treatment cleared $T$. equi infection. All group two and three horses were splenectomized 657-743 days posttreatment. Prior to surgery, each horse underwent a pre-operative physical exam, complete blood count, serum chemistry panel, ECG, and rebreathing exam to ensure it was fit for surgery. Post-operatively, horses received phenylbutazone $(4.4 \mathrm{mg} / \mathrm{kg})$ by mouth once daily for 5 days to minimize pain and were housed in stalls for 60 days following surgery, or until euthanasia.

\subsection{Monitoring for T. equi and T. haneyi recrudescence}

Following surgery, horses were monitored carefully for signs of acute theileriosis as removal of the spleen enables amplification of parasitemia in asymptomatic, persistently $T$. equi-infected horses $[4,6]$. Monitoring consisted of twice daily physical exams, daily CBC, weekly chemistry panel, and daily blood smear to detect inappetence, tachycardia, tachypnea, fever, icterus, hematuria/ hemoglobinuria, parasitemia, anemia, and hyperbilirubinemia [3]. Horses were euthanized if they developed severe clinical signs refractory to supportive care, or when parasitemia levels, based on evaluation of Giemsa-stained blood smears at 100x magnification using oil-immersion, were greater than $25 \%$. In this study, the percent parasitemia was determined using the following equation: ((Total parasites in 5 fields) / (Erythrocyte count in $1 / 4$ of a field $\times 20)$ ) $\times 100$.

Author Contributions: Conceptualization, K.S., L.F., and D.K.; methodology, K.S., D.K., L.F.; formal analysis, K.S., L.F., M.S.; investigation, K.S., P.M., K.D.; resources, D.K. and L.F.; data curation, K.S.; writing-original draft preparation, K.S., L.F.; writing-review and editing, C.O., K.D., P.M., M.S.; visualization, K.S.; supervision, D.K., L.F.; project administration, D.K. and L.F.; funding acquisition, D.K. All authors have read and agreed to the published version of the manuscript.

Funding: The research was funded by USDA-ARS CRIS\# \#2090-320000-034-00D and in part by the Washington State University, College of Veterinary Medicine Equine Infectious Disease Research Program.

Acknowledgements: The authors wish to acknowledge the technical expertise of Shelby Beckner, and the animal handling expertise of Cody Evans, Morgan Burke, Emma Karel, Megan Jacks, and Ralph Horn.

Conflicts of Interest. The author declares no conflict of interest. 


\section{References}

1. Wise, L.N.; Pelzel-McCluskey, A.M.; Mealey, R.H.; Knowles, D.P. Equine piroplasmosis. Vet Clin North Am Equine Pract 2014, doi: 10.1016/j.cveq.2014.08.008.

2. Camino, E.; Pozo, P.; Dorrego, A.; Carvajal, K.A.; Buendia, A.; Gonzalez, S.; de Juan, L.; Dominguez, L.; Cruz-Lopez, F. Importance of equine piroplasmosis antibody presence in spanish horses prior to export. Ticks Tick Borne Dis 2020, 11, 101329,doi: 10.1016/j.ttbdis.2019.101329.

3. Wise, L.N.; Kappmeyer, L.S.; Mealey, R.H.; Knowles, D.P. Review of equine piroplasmosis. J Vet Intern Med 2013, 27, 1334-1346,doi: 10.1111/jvim.12168.

4. $\quad$ Guimarães, A.M.; Lima, J.D.; Tafuri, W.L.; Ribeiro, M.F.B.; Sciavicco, C.J.S.; Botelho, A.C.C. Clinical and histopathological aspects of splenectomized foals infected by babesia equi. J Equine Vet Sci 1997, 17, 211-216,doi: http://dx.doi.org/10.1016/S0737-0806(97)80563-1.

5. Kuttler, K.L.; Gipson, C.A.; Goff, W.L.; Johnson, L.W. Experimental babesia equi infection in mature horses. Am J Vet Res 1986, 47, 1668-1670,

6. Singh, B.; Banerjee, D.P.; Gautam, O.P.; Gupta, R.K.P. Clinicopathological changes in splenectomised donkeys infected with babesia equi. Indian $\mathrm{J}$ Parasitol 1980, 4, 77-80,

7. Ueti, M.W.; Mealey, R.H.; Kappmeyer, L.S.; White, S.N.; Kumpula-McWhirter, N.; Pelzel, A.M.; Grause, J.F.; Bunn, T.O.; Schwartz, A.; Traub-Dargatz, J.L., et al. Re-emergence of the apicomplexan theileria equi in the united states: Elimination of persistent infection and transmission risk. PLoS One 2012, 7, e44713,doi: 10.1371/journal.pone.0044713.

8. Ambawat, H.K.; Malhotra, D.V.; Kumar, S.; Dhar, S. Erythrocyte associated haemato-biochemical changes in babesia equi infection experimentally produced in donkeys. Vet Parasitol 1999, 85, 319-324,

9. $\quad$ Cunha, C.W.; McGuire, T.C.; Kappmeyer, L.S.; Hines, S.A.; Lopez, A.M.; Dellagostin, O.A.; Knowles, D.P. Development of specific immunoglobulin ga (igga) and iggb antibodies correlates with control of parasitemia in babesia equi infection. Clin Vaccine Immunol 2006, 13, 297-300,doi: 10.1128/CVI.13.2.297300.2006.

10. Lewis, M.J.; Wagner, B.; Woof, J.M. The different effector function capabilities of the seven equine igg subclasses have implications for vaccine strategies. Mol Immunol 2008, 45, 818-827,doi: 10.1016/j.molimm.2007.06.158.

11. Knowles, D.P.; Kappmeyer, L.S.; Stiller, D.; Hennager, S.G.; Perryman, L.E. Antibody to a recombinant merozoite protein epitope identifies horses infected with babesia equi. J Clin Microbiol 1992, 30, 3122-3126,

12. Bishop, R.P.; Kappmeyer, L.S.; Onzere, C.K.; Odongo, D.O.; Githaka, N.; Sears, K.P.; Knowles, D.P.; Fry, L.M. Equid infective theileria cluster in distinct $18 \mathrm{~s}$ rna gene clades comprising multiple taxa with unusually broad mammalian host ranges. Parasit Vectors 2020, 13, 261, doi: 10.1186/s13071-020-04131-0.

13. Knowles, D.P.; Kappmeyer, L.S.; Haney, D.; Herndon, D.R.; Fry, L.M.; Munro, J.B.; Sears, K.; Ueti, M.W.; Wise, L.N.; Silva, M., et al. Discovery of a novel 
species, theileria haneyi $\mathrm{n}$. Sp., infective to equids, highlights exceptional genomic diversity within the genus theileria: Implications for apicomplexan parasite surveillance. Int J Parasitol 2018, doi: 10.1016/j.ijpara.2018.03.010.

14. Sears, K.P.; Kappmeyer, L.S.; Wise, L.N.; Silva, M.; Ueti, M.W.; White, S.; Reif, K.E.; Knowles, D.P. Infection dynamics of theileria equi and theileria haneyi, a newly discovered apicomplexan of the horse. Vet Parasitol 2019, 271, 68-75,doi: 10.1016/j.vetpar.2019.06.009.

15. Coultous, R.M.; McDonald, M.; Raftery, A.G.; Shiels, B.R.; Sutton, D.G.M.; Weir, W. Analysis of theileria equi diversity in the gambia using a novel genotyping method. Transbound Emerg Dis 2019, doi: 10.1111/tbed.13454.

16. Bhoora, R.V.; Collins, N.E.; Schnittger, L.; Troskie, C.; Marumo, R.; Labuschagne, K.; Smith, R.M.; Dalton, D.L.; Mbizeni, S. Molecular genotyping and epidemiology of equine piroplasmids in south africa. Ticks Tick Borne Dis 2019, 101358,doi: 10.1016/j.ttbdis.2019.101358.

17. Mshelia, P.W.; Kappmeyer, L.; Johnson, W.C.; Kudi, C.A.; Oluyinka, O.O.; Balogun, E.O.; Richard, E.E.; Onoja, E.; Sears, K.P.; Ueti, M.W. Molecular detection of theileria species and babesia caballi from horses in nigeria. Parasitology research 2020, 119, 2955-2963,doi: 10.1007/s00436-020-06797-y.

18. Frerichs, W.M.; Allen, P.C.; Holbrook, A.A. Equine piroplasmosis (babesia equi): Therapeutic trials of imidocarb dihydrochloride in horses and donkeys. Vet Rec 1973, 93, 73-75,doi: 10.1136/vr.93.3.73.

19. Grause, J.F.; Ueti, M.W.; Nelson, J.T.; Knowles, D.P.; Kappmeyer, L.S.; Bunn, T.O. Efficacy of imidocarb dipropionate in eliminating theileria equi from experimentally infected horses. Vet J 2013, 196, 541-546,doi: 10.1016/j.tvjl.2012.10.025.

20. Meyer, C.; Guthrie, A.J.; Stevens, K.B. Clinical and clinicopathological changes in 6 healthy ponies following intramuscular administration of multiple doses of imidocarb dipropionate. J S Afr Vet Assoc 2005, 76, 26-32,doi: 10.4102/jsava.v76i1.390.

21. Adams, L.G. Clinicopathological aspects of imidocarb dipropionate toxicity in horses. Res Vet Sci 1981, 31, 54-61,

22. Kutscha, J.; Sutton, D.G.; Preston, T.; Guthrie, A.J. Equine piroplasmosis treatment protocols: Specific effect on orocaecal transit time as measured by the lactose 13c-ureide breath test. Equine Vet J Supp/ 2012, 62-67,doi:

10.1111/j.2042-3306.2012.00656.x.

23. Wise, L.N.; Kappmeyer, L.S.; Silva, M.G.; White, S.N.; Grause, J.F.; Knowles, D.P. Verification of post-chemotherapeutic clearance of theileria equi through concordance of nested pcr and immunoblot. Ticks Tick Borne Dis 2018, 9, 135140,doi: 10.1016/j.ttbdis.2017.08.007.

24. Hines, S.A.; Ramsay, J.D.; Kappmeyer, L.S.; Lau, A.O.; Ojo, K.K.; Van Voorhis, W.C.; Knowles, D.P.; Mealey, R.H. Theileria equi isolates vary in susceptibility to imidocarb dipropionate but demonstrate uniform in vitro susceptibility to a bumped kinase inhibitor. Parasit Vectors 2015, 8, 33,doi: 10.1186/s13071-0140611-6.

25. Pasolini, M.P.; Pagano, T.B.; Costagliola, A.; Biase, D.; Lamagna, B.; Auletta, L.; Fatone, G.; Greco, M.; Coluccia, P.; Vincenzo, V., et al. Inflammatory myopathy 
in horses with chronic piroplasmosis. Vet Pathol 2018, 55, 133-143,doi: $10.1177 / 0300985817716262$.

26. Butler, C.M.; Werners, A.H.; de Haseth, O.B.; van Maanen, C. Strain variations might determine the effectiveness of multiple high doses imidocarb dipropionate treatment in $t$. Equi carrier horses. In 6th Congress of the European College of Equine Internal Medicine J Vet Int Med: Le Touquet, France, 2013; pp 696-710.

27. De Waal, D.T.; Van Heerden, J.; Van den Berg, S.S.; Stegmann, G.F.; Potgieter, F.T. Isolation of pure babesia equi and babesia caballi organisms in splenectomized horses from endemic areas in south africa. Onderstepoort $J$ Vet Res 1988, 55, 33-35,

28. Bushman, M.; Morton, L.; Duah, N.; Quashie, N.; Abuaku, B.; Koram, K.A.; Dimbu, P.R.; Plucinski, M.; Gutman, J.; Lyaruu, P., et al. Within-host competition and drug resistance in the human malaria parasite plasmodium falciparum. Proc Biol Sci 2016, 283, 20153038,doi: 10.1098/rspb.2015.3038.

29. Hansen, J.; Day, T. Coinfection and the evolution of drug resistance. J Evol Biol 2014, 27, 2595-2604,doi: 10.1111/jeb.12518.

30. Karvonen, A.; Jokela, J.; Laine, A.L. Importance of sequence and timing in parasite coinfections. Trends Parasitol 2019, 35, 109-118,doi:

10.1016/j.pt.2018.11.007.

31. Gimenez, F.; Hines, S.A.; Evanoff, R.; Ojo, K.K.; Van Voorhis, W.C.; Maly, D.J.; Vidadala, R.S.R.; Mealey, R.H. In vitro growth inhibition of theileria equi by bumped kinase inhibitors. Vet Parasitol 2018, 251, 90-94,doi: 10.1016/j.vetpar.2017.12.024.

32. M, G.S.; Knowles, D.P.; Antunes, S.; Domingos, A.; Esteves, M.A.; Suarez, C.E. Inhibition of the in vitro growth of babesia bigemina, babesia caballi and theileria equi parasites by trifluralin analogues. Ticks Tick Borne Dis 2017, 8, 593-597,doi: 10.1016/j.ttbdis.2017.04.002.

33. Silva, M.G.; Villarino, N.F.; Knowles, D.P.; Suarez, C.E. Assessment of draxxin(®) (tulathromycin) as an inhibitor of in vitro growth of babesia bovis, babesia bigemina and theileria equi. Int J Parasitol Drugs Drug Resist 2018, 8, 265-270,doi: 10.1016/j.ijpddr.2018.04.004.

34. Bowden, G.D.; Reis, P.M.; Rogers, M.B.; Bone Relat, R.M.; Brayton, K.A.; Wilson, S.K.; Di Genova, B.M.; Knoll, L.J.; Nepveux, V.F.; Tai, A.K., et al. A conserved coccidian gene is involved in toxoplasma sensitivity to the antiapicomplexan compound, tartrolon e. Int J Parasitol Drugs Drug Resist 2020, 14, 1-7,doi: 10.1016/j.jpddr.2020.07.003.

35. O'Connor, R.M.; Nepveux, V.F.; Abenoja, J.; Bowden, G.; Reis, P.; Beaushaw, J.; Bone Relat, R.M.; Driskell, I.; Gimenez, F.; Riggs, M.W., et al. A symbiotic bacterium of shipworms produces a compound with broad spectrum antiapicomplexan activity. PLoS Pathog 2020, 16, e1008600,doi: 10.1371/journal.ppat.1008600.

36. Bertone, J.G., H; Sislak, M; Agnic, H; Heidmiller, M; Stanley, S; Wickler, S. In Pharmacokinetics, pharmacodynamics, and safety of n-butylscopolammonium bromide administered intramuscularly versus intravenously, AAEP, Baltimore, MD, December 4-8, 2010, 2010; American Association of Equine Practitioners: Baltimore, MD, pp 279-280. 
37. Ueti, M.W.; Palmer, G.H.; Scoles, G.A.; Kappmeyer, L.S.; Knowles, D.P. Persistently infected horses are reservoirs for intrastadial tick-borne transmission of the apicomplexan parasite babesia equi. Infect Immun 2008, 76, 35253529,doi: 10.1128/iai.00251-08.

38. Roberts, M.C.; Groenendyk, S. Splenectomy in the horse. Aust Vet J 1978, 54, 196-197,doi: 10.1111/j.1751-0813.1978.tb02450.x. 